\title{
A Review of the Application of Optical and Radar Remote Sensing Data Fusion to Land Use Mapping and Monitoring
}

\author{
Neha Joshi ${ }^{1, *}$, Matthias Baumann ${ }^{2,+}$, Andrea Ehammer ${ }^{1,+}$, Rasmus Fensholt ${ }^{1,+}$, \\ Kenneth Grogan 1,t , Patrick Hostert 2,3,t, Martin Rudbeck Jepsen 1,t , Tobias Kuemmerle 2,3,t, \\ Patrick Meyfroidt 4,5, ${ }^{4}$, Edward T. A. Mitchard ${ }^{6,+}$, Johannes Reiche ${ }^{7,+}$, Casey M. Ryan ${ }^{6, t}$ \\ and Björn Waske ${ }^{8, t}$
}

Received: 21 October 2015; Accepted: 8 January 2016; Published: 16 January 2016

Academic Editors: Linda See, Martin Herold, Magaly Koch and Prasad S. Thenkabail

1 Department of GeoSciences and Natural Resource Management, University of Copenhagen, Copenhagen 1165, Denmark; andrea.ehammer@ign.ku.dk (A.E.); rf@ign.ku.dk (R.F.); kenneth.grogan@ign.ku.dk (K.G.); mrj@ign.ku.dk (M.R.J.)

2 Geography Department, Humboldt-University Berlin, Unter den Linden 6, Berlin 10099, Germany; matthias.baumann@geo.hu-berlin.de (M.B.); patrick.hostert@geo.hu-berlin.de (P.H.); tobias.kuemmerle@geo.hu-berlin.de (T.K.)

3 Integrative Research Institute on Transformations of Human-Environment Systems (IRI THESys), Humboldt-University Berlin, Unter den Linden 6, Berlin 10099, Germany

4 F.R.S.-FNRS, Brussels 1000, Belgium; patrick.meyfroidt@uclouvain.be

5 Earth and Life Institute (ELI), Université Catholique de Louvain, Louvain-La-Neuve 1348, Belgium

6 School of GeoSciences, University of Edinburgh, Edinburgh EH9 3FF, UK; edward.mitchard@ed.ac.uk (E.T.A.M.); casey.ryan@ed.ac.uk (C.M.R.)

7 Laboratory of Geo-Information Science and Remote Sensing, Wageningen University, Droevendaalsesteeg 3, Wageningen 6708 PB, The Netherlands; johannes.reiche@wur.nl

8 Institute of Geographical Sciences, Freie Universität Berlin, Malteserstr. 74 - 100, Berlin 12249, Germany; bjoern.waske@fu-berlin.de

* Correspondence: npjo@ign.ku.dk; Tel.: +45-353-31897

+ These authors contributed equally to this work.

\begin{abstract}
The wealth of complementary data available from remote sensing missions can hugely aid efforts towards accurately determining land use and quantifying subtle changes in land use management or intensity. This study reviewed 112 studies on fusing optical and radar data, which offer unique spectral and structural information, for land cover and use assessments. Contrary to our expectations, only 50 studies specifically addressed land use, and five assessed land use changes, while the majority addressed land cover. The advantages of fusion for land use analysis were assessed in 32 studies, and a large majority (28 studies) concluded that fusion improved results compared to using single data sources. Study sites were small, frequently $300-3000 \mathrm{~km}^{2}$ or individual plots, with a lack of comparison of results and accuracies across sites. Although a variety of fusion techniques were used, pre-classification fusion followed by pixel-level inputs in traditional classification algorithms (e.g., Gaussian maximum likelihood classification) was common, but often without a concrete rationale on the applicability of the method to the land use theme being studied. Progress in this field of research requires the development of robust techniques of fusion to map the intricacies of land uses and changes therein and systematic procedures to assess the benefits of fusion over larger spatial scales.
\end{abstract}

Keywords: optical; synthetic aperture radar; meta-analysis; Landsat; ALOS PALSAR; ERS-1 and -2; land cover; decision tree; machine learning; pixel- and segment-level analyses 


\section{Introduction}

Anthropogenic land use and cover change (LUCC) is a major cause of global environmental change [1]. The conversion of natural lands into human-dominated landscapes has been substantial during the past few centuries, but dramatically accelerated during the last two to three decades [2] and is expected to continue in the absence of altered human activities [3]. The transition of forests and grasslands to crop lands and pastures is the most prevalent of these changes, linked to increasing demand for food and fibre, with impacts on carbon stocks [4,5], biodiversity [6] and climate [7]. Alongside these changes, land is being subtly modified to alter ecosystem services (e.g., through selective log harvesting or agricultural intensification) by processes that are poorly quantified to date, but carry substantial environmental costs [8]. Understanding the processes of LUCC is of paramount importance towards more sustainable land management and will aid global initiatives, such as reducing emissions from deforestation and forest degradation (REDD+) [9,10]. However, quantifying LUCC remains a challenge, partly since the dynamics and trajectories of change are complex and fast-evolving $[3,11]$ and partly since robust methods for analyses are still in development for many LUCC processes.

The umbrella concept of LUCC entails both the complete conversion or more subtle modification of land cover and complete changes in land use or subtle alterations in land management (Figure 1). Land cover commonly refers to the physical properties of a land surface [2], typically represented in maps as classes of different vegetation cover (e.g., woody vegetation, grasslands, etc.) or surfaces (e.g., water bodies, bare soils, etc.). Land cover conversion is defined as a shift from one land cover class to another and modification as subtle changes in continuous properties within classes (e.g., plant biomass, canopy cover, leaf area [12,13]). Land use, by contrast, corresponds to the activities or functions for which humans utilize land [2]. Land use change may entail both the adoption of new uses (e.g., forestry or agricultural expansion into previously unmanaged forests) or changes in management within a land use class, usually as changes in input intensity (e.g., fertilizer application rates, mechanization levels) and/or outputs (e.g., logging or harvesting frequency and production) [14]. Land use and land cover are inherently related, but are nevertheless conceptually distinct, and drawing relations between the two is not straightforward, since multiple relations exist in the pathways of change within and across land cover and land use categories (Figure 1). For example, changes in land use can occur with or without a conversion of the broad land cover class (e.g., when ranching expands into forests or natural grasslands) or a gradual change in land management can eventually trigger land cover conversion (e.g., increasing grazing pressure may trigger bush encroachment and a shift from grasslands to woody savannahs [15]). Land cover changes may not necessarily result from direct human activities and land use alone, but also from natural processes [15-20].

Decades of scientific research have shown considerable progress towards assessing LUCC [1]. Using air- or space-borne remote sensing data is a fast-advancing approach in this field [21-26], particularly due to its ability to provide regular spatially- and temporally-explicit data across large areas when compared to field-based assessments. Remote sensors operate on a variety of basic physical principles, recording the electromagnetic properties of a land surface (either the energy reflected (optical sensors), emitted (thermal infrared or passive microwave sensors) or scattered (active radar sensors)) and, hence, provide a variety of information on land properties. However, considerable challenges to mapping LUCC using remote sensing data persist; the data are not always uniquely linked to land cover and are ambiguously related to land use, hence commonly requiring the use of heuristic, empirical, e.g., [11,27], or physically-based models [28] to infer land properties. Further, land use information must often be inferred based on integration with ground-knowledge or user interpretation $[27,29]$. Reliable, regular and extensive ground assessments are expensive and challenging, often constraining remote sensing to mapping unambiguous land cover properties only. Consequently, mapping the complexity of changes and subtle modifications in land use management, 
which are paramount to monitoring the environmental and societal impacts of land use [30,31], remains understudied [32].

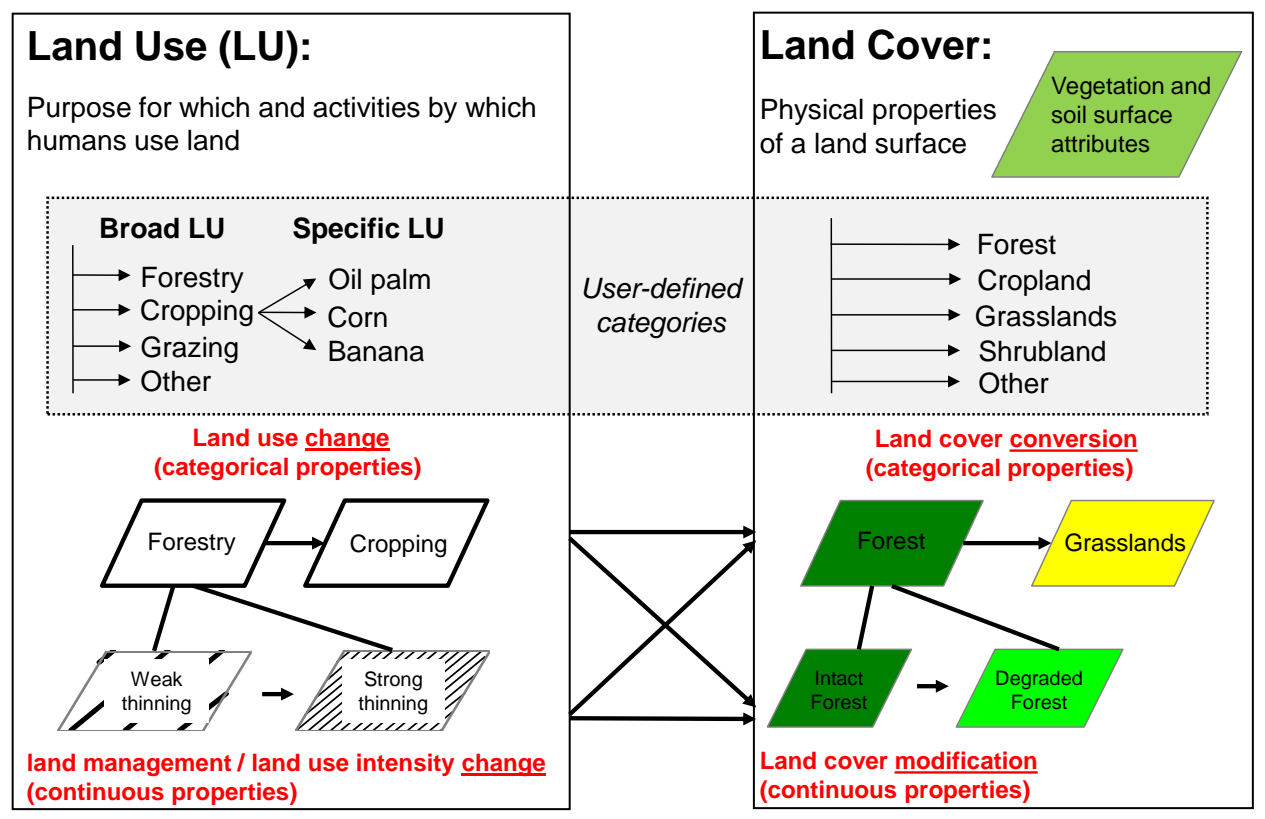

Figure 1. Conceptual sketch and examples of the relations between land use and land cover conversions and modifications.

To overcome this limitation and improve the identification of land use dynamics specifically, fusing datasets acquired from remote sensors that operate on different fundamental physical principles, and hence, providing synergistic information on land properties, appears to be a promising approach. Particularly with the prospects of multiple datasets of free images being available (e.g., optical and radar images from the Sentinel satellite series [33]), fusion brings the benefits of higher spectral resolution, compensating for the limitations of using single data products alone. Based on this hypothesis, this review focuses on examining the utility of combining two types of remote sensing data, optical and radar (synthetic aperture radar (SAR), scatterometer or radar altimeter), for characterizing land use and changes therein, as reported in studies to date. The complementarity of these two types of data [34] is hypothesized to be able to provide enhanced information on land cover and use. For example, optical energy reflected by vegetation is dependent on leaf structure, pigmentation and moisture, while active microwave energy scattered by vegetation is dependent on the size, density, orientation and dielectric properties of elements comparable to the size of the radar wavelength. Optical products are commonly available as multispectral images (ranging from visible to infrared wavelengths) consisting of several bands of data, which can offer different information on land properties based on its spectral reflectance, as well as be used to accentuate land cover through various indices (e.g., Normalized Difference Vegetation Index (NDVI)). In contrast, radar signals are typically only generated at a single wavelength for each sensor, and interact in a characteristic way with structural land properties (e.g., in forests, backscattered energy from active radar signals is returned primarily from canopies and stems and depending on the wavelength and incidence angle of the radar pulses used, differences in the roughness and moisture content of these surfaces may be extracted). Multiple bands of SAR backscatter can however be composed of polarized combinations of the signals transmitted to, and received back from, land surfaces (e.g., horizontal send and horizontal receive, $\mathrm{HH}$, and horizontal send and vertical receive, HV), 
and the intensity and polarization can provide insight into the scattering mechanisms and, hence, the physical structure of scattering elements. Furthermore, techniques, such as interferometric SAR (InSAR), make use of differential phases of reflected signals to detect land surface changes and can be used for mapping various land cover and use properties [35,36].

Quantifying and mapping the subtle and more complex properties of land use (e.g., input or output intensity, abandonment and fallow cycles, irrigation frequencies etc. [30]) (Figure 1) potentially stand to gain most from the integration of optical and radar data. For example, a major current concern raised in the land systems literature today is understanding specific land use trajectories of different commodity crops, i.e., the share of deforestation caused or the sources of land for different crop types [37-39]. Improved ability to differentiate specific crops within broad crop land classes would strongly benefit this research, allowing understanding the complex linkages between different commodities and targeting interventions to improve the sustainability of commodity-specific supply chains [40,41]. Optical data may provide more robust and interpretable images for delineating broad land use and cover classes, which, added to the information provided by radar images on surface roughness and moisture, can allow more detailed characterization of land management and modifications. Several aspects of land use intensity could then benefit from this combination, including measures of inputs' intensity, such as irrigation and tillage. Such land use intensity data could, for example, benefit precision farming by allowing farmers to precisely control irrigation and nutrient inputs and to catch diseases or under-performing crops early. Advances in regular measures of output intensity (e.g., growth and harvest rates) could come from improved biomass estimates, by combining information from optical sensors on photosynthetic activity (e.g., NDVI) with radar-derived information on crop structure and volume. Such a combination would also allow the processing of enhanced information on land use in complex agroforestry or shifting cultivation landscapes, as well as separating tree plantations from natural forests. Improved characterization of such mosaic landscapes and forest disturbances would, in turn, allow one to more precisely understand the causes of forest degradation and regeneration.

While the complementarity of data from both optical and radar sensors for the characterization of LUCC has been put to use in many very recent studies, e.g., [42-47], the development of adequate data fusion techniques is an important ongoing field of research [48]. In general, fusion refers to a formal concept for combining data from different sources [49,50], with the aim of generating information of "greater quality" than the individual input datasets. The definition of "greater quality" varies highly depending on the field of application (e.g., LUCC) of fusion [51]. Methods of image fusion can be grouped into three categories depending on the level at which the integration is performed: (i) pixel-level fusion (data fusion); (ii) feature fusion; and (iii) decision fusion. The first category refers to the combination of the original image pixels, while the second is based on combining features extracted from the individual datasets [46,52-54]. In contrast, decision fusion requires preliminary analysis of the different datasets, e.g., the separate classifications of optical and SAR data, after which outputs are combined to generate a final result, e.g., [43,55,56]. The first two methods could be considered "pre-classification or -modelling fusion", whereas the final method is "post-classification or -modelling fusion".

Users can thus choose between several techniques for image fusion, in addition to a wide choice of radar and optical sensors. Further, within each fusion technique, there is a variety of methods that can be used, leading to inconsistencies between studies that pose problems for replicating and conducting consistent LUCC assessments [57]. A review of the status of synergistic applications is crucial to identify current knowledge and methodological gaps and to focus future research on the most promising results and critical shortcomings of the combined use of these products. In this review, we address three overarching questions:

R1: What land use and land cover types, and the changes therein, have been analysed using the integration of optical and radar remote sensing data? 
R2: What combination of optical and radar sensors was most popular in studies assessing land use and land use changes, and what spatial scales were analysed?

R3: How was the analysis of the fusion of optical and radar data conducted, and did fusion result in a more accurate assessment of land use and the changes therein?

As data complementarity, availability and quality are core parameters for fusion, Section 2 briefly summarizes the role of optical and radar sensors in previous LUCC studies.

\section{Remote Sensing for LUCC Analyses}

\subsection{Optical Remote Sensing}

Optical remote sensing has offered data for over four decades, with a few systems dominating LUCC analyses due to the length of consistent datasets or the ease of availability (e.g., Landsat since 1972, the Landsat Thematic Mapper since 1983, Satellite Pour l'Observation de la Terre (SPOT) since the mid-1980s and the Moderate Resolution Imaging Spectroradiometer (MODIS) since 1999). Regional or national-scale land mapping studies often use products with a medium-to-high spatial resolution (e.g., $<100 \mathrm{~m}$ ), such as Landsat or SPOT, e.g., [58-60], although increasing computing power has also recently allowed such data to be analysed at a global scale, e.g., [26]. Global land mapping programs generally use coarser spatial resolution $(\geq 250 \mathrm{~m})$ data, such as the Medium Resolution Imaging Spectrometer (MERIS) for GLOBCOVER [61], SPOT VEGETATION for the Global Land Cover 2000 dataset [62], the Advanced Very High Resolution Radiometer (AVHRR) for the University of Maryland Global Land Cover Classification [63] or the MODIS global land cover product [64]. Although lacking high spatial detail, the daily or near-daily temporal resolution of such sensors enables frequent analyses. Increasingly, studies address approaches that analyse dense time series of optical data $[65,66]$ or complement them with spatially-explicit statistical data [67], making use of the vast amount of optical data that is freely available, especially the Landsat archive $[26,68,69]$. Analyses with dense time series have an advantage of being able to capture both highly dynamic and gradual or long-term change processes compared to traditional multi-temporal image classifications alone [70], as well as overcoming gaps due to cloud cover [71,72].

\subsection{Radar Remote Sensing}

The use of microwave technology for mapping land has not been as widespread as that of optical remote sensing, gaining pace mostly in the last one or two decades. Notably, data from a number of past and current spaceborne SAR systems-Spaceborne Imaging Radar-C/X-Band Synthetic Aperture Radar (SIR-C/X-SAR), European Remote Sensing (ERS-1 and -2), Advanced Synthetic Aperture Radar (ASAR), Japanese Earth Resources Satellite (JERS-1), RADARSAT-1 and -2, Advanced Land Observation Satellite (ALOS-1) —are commonly in use and applied at regional-scales, with very few studies addressing global-scale mapping, e.g., [73]. Studies have covered a variety of themes related to land cover, including improved land cover classifications [35,74], forest cover classifications [75], grassland monitoring [47], identification of degraded woodlands [27,76,77] and mapping deforestation [78] and successional forest dynamics [11]. Similarly, land use-specific studies have focussed on various themes, including urban land use analysis $[79,80]$, classification of agricultural areas [81], mapping and monitoring specific crop types (e.g., rice [82-84]), etc. Increasingly, radar data have been exploited in combination with optical data for improved crop classifications $[45,85,86]$ and mapping land management regimes $[46,87]$.

\subsection{Limitations of Optical and Radar Products}

Cloud cover severely limits the use of optical products $[88,89]$ and can be reduced by using image compositing [26,90,91], however constraining multi-temporal change analysis as a result. Methodological, optical-based analyses are also limited by the similarities in spectral reflectance 
across a landscape (e.g., different agricultural crops or tree species with similar phenological characteristics may be indistinguishable) and, hence, by the inability to distinguish land uses that result in similar land cover features. Optical sensors also only detect surface tops, meaning that forest canopy obscures the understory and crops obscure soil, limiting the inferences of land cover and land use to only when these are correlated well with the characteristics of top layers. Changes in the spectral properties of the soil and atmosphere (e.g., from smoke) can also hinder the inference of land and vegetation properties.

Similarly, there are a number of challenges to analysing and interpreting radar images for land applications [92]. Speckle, which is inherent in all SAR images, may increase measurement uncertainty and result in poor classification accuracies [93], requiring pre-analysis spatial or temporal speckle reduction filters, e.g., [94,95]. Topography is a major limitation in mountainous regions due to geometric and radiometric effects (e.g., radar shadow caused by foreshortening and layover) when data are mapped to ground-range images [96]. Furthermore, since SAR observations require a relatively high energy provision on satellite platforms, the availability of dense time series of SAR data or even single observations is scarce in many regions of the world. Until recently, satellite-based SAR data for large-scale multi-temporal assessments were constrained by low spatial and temporal coverage of medium resolution data, particularly C-band (wavelength $\sim 6 \mathrm{~cm}$ ) or L-band (wavelength $\sim 23 \mathrm{~cm}$ ) data [97], which may now be overcome with acquisitions from the recently launched C-band Sentinel-1 and L-band ALOS-2 satellite missions.

In summary, despite the complementarity of the optical and radar datasets, their individual limitations pose challenges to mapping land properties. However, most of these limitations do not overlap between the two datasets (with exceptions, such as topography, which can affect both radar and optical data), such that complementarity is feasible, and one dataset may compensate for the shortcomings of the other. For example, since microwaves in the widely-used SAR wavelength range (approximately a few centimetres to meters) are not affected by smoke, atmospheric haze or cloud cover, radar can fill gaps in cloudy regions, e.g., [98]. Hence, the synergism of the information contained within both datasets may successfully be used for LUCC analysis.

\section{Methods}

Structured queries on Web of Science (http:/ /apps.webofknowledge.com/) using combinations of key terms and their synonyms related to land use and cover (Table 1) were conducted from 1 November 2014-26 June 2015. The search was restricted to results of articles and reviews, leading to an initial gross selection of 739 papers. Based on the abstracts of these papers, studies where key terms were present, but that did not address any form of integration of radar and optical data for analysis were excluded. Studies that did not refer to any form of land vegetation or use, e.g., studies on geological formations, water bodies or soil moisture, were also excluded.

The resulting set of studies (112 articles and reviews; Supplementary 1) were then analysed to identify if the fusion of optical and radar data was focused on studying land cover, land use or the changes therein. For consistency, the definitions of land use and land cover described in this study (Section 1) were used, since a large number of studies used both terms interchangeably. A number of studies also focussed on multiple themes related to land use/cover, but used data fusion to address only a few of their target research questions (e.g., using fusion to classify land cover, but only either optical or radar data, without fusion, to identify specific land uses). Hence, our analysis reports on those sections and aims of articles for which fusion was performed. Further, this review aims to identify the progress and benefits of data fusion applied specifically to land use assessments (including land use management), which are generally challenging to conduct using single data sources. Hence, studies that addressed land use (e.g., land use classifications, land management, intensity of land use, etc.) and that did not only focus on land cover or changes therein were examined further. A review of the sensors used, the size and locations of the study areas covered, the methods applied and the benefits of fusing optical and radar data was conducted for these studies. 
Table 1. Search terms used to select studies for review and the initial number of results for each search category.

\begin{tabular}{|c|c|}
\hline TERMS & $\begin{array}{c}\text { RESULTS } \\
\text { (Articles and Reviews) }\end{array}$ \\
\hline $\begin{array}{c}\text { (radar OR scatteromet* OR microwave* OR SAR*) AND optical AND } \\
\text { (integrat* OR synerg* OR combin* OR fus* OR compar* OR multi* OR mix*) } \\
\text { AND (forest* OR savann* OR woodland) }\end{array}$ & 280 \\
\hline $\begin{array}{c}\text { (radar OR scatteromet* OR microwave* OR SAR*) AND optical AND } \\
\text { (integrat* OR synerg* OR combin* OR fus* OR compar* OR multi* OR mix*) } \\
\text { AND (agricultur }{ }^{*} \text { OR } \text { crop }^{*} \text { OR farm*) }\end{array}$ & 240 \\
\hline $\begin{array}{c}\text { (radar OR scatteromet* OR microwave* OR SAR*) AND optical AND } \\
\text { (integrat* OR synerg* OR combin* OR fus* OR compar* OR multi* OR mix*) } \\
\text { AND (grazing OR pasture OR pastor* OR grass*) }\end{array}$ & 95 \\
\hline $\begin{array}{c}\text { (radar OR scatteromet* OR microwave* OR SAR*) AND optical AND } \\
\text { (integrat* OR synerg* OR combin* OR fus* OR compar* OR multi* OR mix*) } \\
\text { AND (land use OR land cover) }\end{array}$ & 397 \\
\hline
\end{tabular}

\section{Results}

The 112 short-listed studies were published between 1996 and 2015 by 95 first-authors from over 90 institutions based in over 30 countries, providing a diverse sample of studies to review. Each study was given a unique ID detailed in Appendix 1, referred to in this section.

\subsection{Overview of the Characteristics of Land Use or Cover Studied}

All of the studies short-listed in the search were first categorized based on the target question R1, i.e., what types of land use and land cover, and changes therein, were analysed, by addressing sub-questions R1.1-R1.4 as described below.

R1.1. How was land characterized or mapped: (i) as discrete classes; (ii) with continuous land properties; or (iii) both? What types of land cover and land use were studied?

The majority of studies (75 of 112 studies) described land in discrete classes (e.g., as classifications), while the remainder characterized continuous properties of land surfaces. Studies exploring continuous land properties mainly looked at forest properties (e.g., biomass (e.g., ID 51, 53, $59,99)$, forest stand height (e.g., ID 109); 24 of 37 studies). Fewer studies used continuous properties to describe crop lands (e.g., yields (e.g., ID 27), leaf area index (e.g., ID 6, 38); 9 of 37 studies) and grasslands (e.g., biomass (e.g., ID 65); 7 of 37 studies)

R1.2. How was land use characterized: (i) as broad land use classes (e.g., crop land, forests, wetlands); (ii) as specific land use classes (e.g., specific crop types, various pasture classes); (iii) with continuous variables measuring land use properties or land management and use intensity; or (iv) was it not addressed (i.e., did studies address only land cover)?

Many studies (62 of 112 studies) addressed only land cover, but not land use, as defined in this review (Section 1) (Table 2). Most studies looking at land use (50 of 112 studies) used a combination of radar and optical data to distinguish specific land use classes, such as various crops (e.g., ID 3, 31, 32, 35), different categories of crop land (e.g., planted versus non-planted paddy (e.g., ID 34), irrigated, rainfed or tilled crop land (e.g., ID 18, 26)), permanent crop types (e.g., olive groves (e.g., ID 37), palm plantations (e.g., ID 40), rubber (e.g., ID 9), Eucalyptus (e.g., ID 39)) or different types and conditions of pasture (e.g., ID 20) or of logging (e.g., ID 14, 42) (37 of 50 studies). Some of these classes were aimed at indicating land use intensity (e.g., small-scale crop land versus large-scale intensive cropping (e.g., ID 45)), but still operated with discrete land classes. Only a small set of studies (6 of 50 studies) mapped broad categories of land use (e.g., wetlands, agriculture, urban areas and forests, without distinguishing specific land uses within each category). A handful of studies 
(7 of 50 studies) characterized continuous variables related directly to land management or use intensity (e.g., frequency of harvests (ID 47)), or continuous variables not necessarily directly reflecting land use intensity (e.g., rubber tree cover fraction (ID 8), or classification of the Brazilian Cerrado with different degradation intensity (ID 4)).

Table 2. Summary of land use or land cover characterized in the studies.

\begin{tabular}{cc}
\hline Land Use/Cover and Change Characterization & Number of Studies \\
\hline Broad land uses & 6 \\
Including land use/cover change & 0 \\
Specific land uses & 37 \\
Studies including change & 3 \\
\hline Continuous properties of land use/land management/land use intensity & 7 \\
Studies including change & 2 \\
\hline Land use not addressed (land cover only) & $\mathbf{6 2}$ \\
Studies including change & 6 \\
Studies characterizing change as modification & 5 \\
\hline Total & 1 \\
\hline
\end{tabular}

R1.3. Was land use/cover change characterized as: (i) conversion from one class to another; (ii) modification in a continuous variable; or (iii) was it not addressed?

Very few studies addressed aspects of land use/cover change (ID 6, 14, 17, 42, 43, 56, 65, 95, 96, 98,$104 ; 11$ of 112 studies), and no study investigated both anthropogenic and natural environmental factors together as drivers of change. Of the three studies measuring specific land uses and performing change detection, one detected changes in agricultural areas (ID 43); one combined land use mapping with land cover changes through fire conversion (ID 42); and one detected clear-felled areas (ID 14). Overall, more studies addressed gradual changes (i.e., land modifications, management or intensity changes) than land cover conversions or shifts among land use classes (7 and 4 of 11 studies, respectively).

R1.4. What types of land use/cover categories were covered by the studies?

The majority of studies (71 of 112 studies) focussed on a single type of land use/cover category, i.e., either cropping, grasslands/shrublands/pastures, forests, wetlands, savannah/woodlands or urban areas, with the remaining studies included two or more categories (Figure 2). Those that focussed on a single class primarily dealt with forests (37 of 71 studies) or cropping (18 of 71 studies), while wetlands, savannahs/woodlands and urban areas were least studied (7, 2 and 1 of 71 studies, respectively). In studies that addressed land use, half (24 of 50 studies) focussed on a single class, which was mostly cropping (16 of 24 studies), while grasslands/shrublands/pastures and wetlands were less studied ( 1 each of 24 studies, respectively), and no studies addressed savannah/woodlands or urban land use exclusively.

Forests were the most represented form of land cover in the studies (43 of 62 studies), followed by grasslands, wetlands and savannah/woodlands (15, 12 and 9 of 62 studies, respectively). In studies that specifically analysed land use, those including cropping constituted the majority (39 of 50 studies), followed by forests and forestry (27 of 50 studies) and grasslands/shrublands/pastures (19 of 50 studies), while savannah/woodlands, wetlands and urban land use were the least addressed (3, 9 and 12 of 50 studies, respectively). 

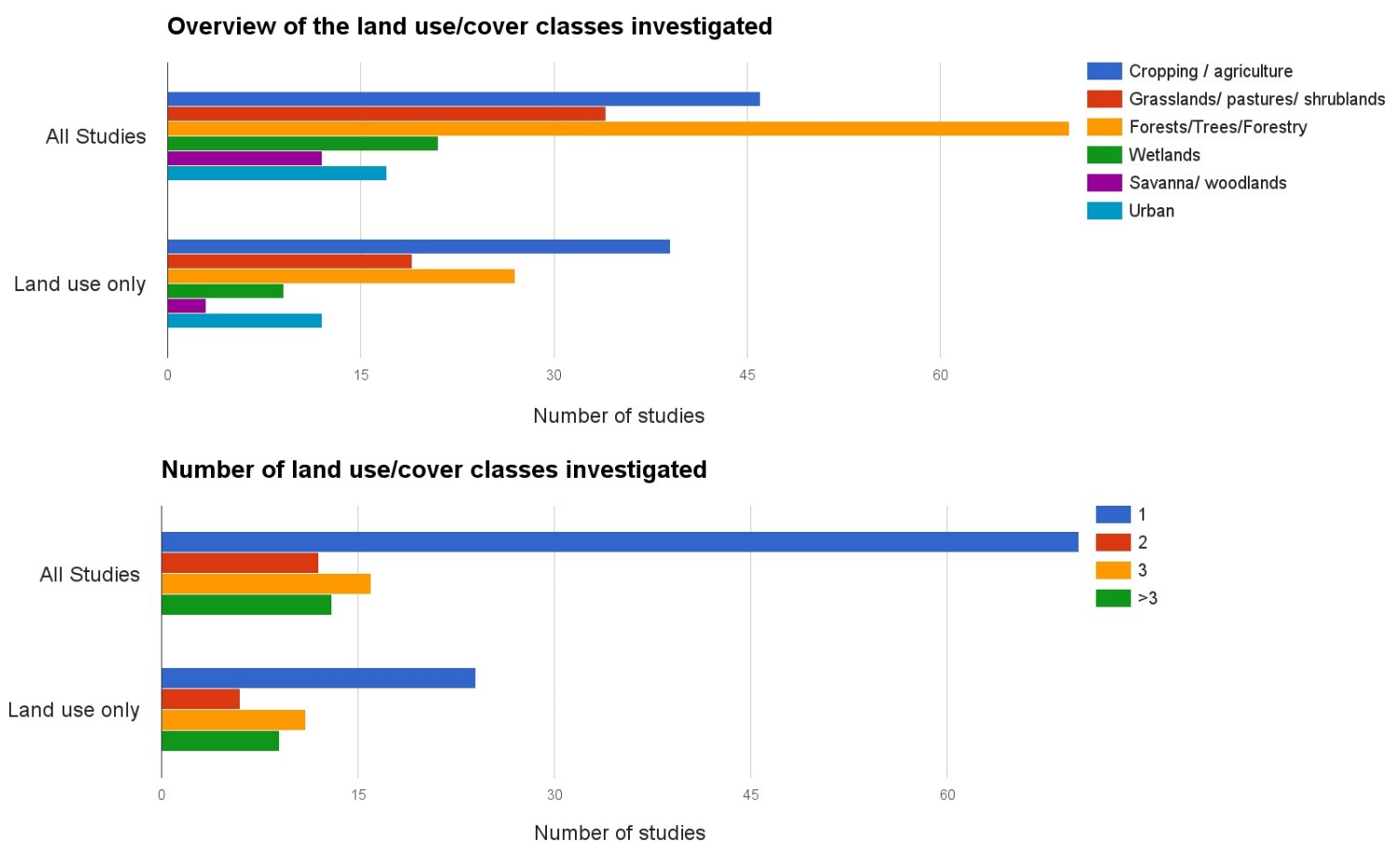

Figure 2. Summary of land use/cover classes included in the studies.

\subsection{Characteristics of Studies Addressing Land Use}

The 50 studies that specifically addressed aspects of land use (Table 2) were further categorized based on the target question R2, i.e., what spatial scales and types of sensors were used, by addressing sub-questions R2.1-R2.2 as described below.

R2.1. Where were studies applied (geographically), and what was the spatial scale (extent, resolution) of the assessments?

Locations in Europe dominated most study-sites in articles that assessed land use (17 of 50 studies), followed by Africa and Asia (9 of 50 studies each) (Figure 3). The nationality of the institution of the first authors revealed that U.S. and German institutions produced a sizeable amount of research (11 and 5 studies, respectively), which was not restricted to only domestic sites, but also covered sites in Sudan, Kenya, Benin, Tanzania, Brazil, Ecuador, Ukraine, China and Indonesia. A number of assessments were conducted at the plot level (e.g., on individual agricultural farms) (8 of 50 studies overall), implying that the actual spatial expanse of many studies was small. Most other studies were restricted to between 300 and $3000 \mathrm{~km}^{2}$ (14 of 50 studies) (Figure 4).

R2.2. What combination of sensors have been used in studies?

The most commonly-used combination of optical and radar sensors included Landsat and ALOS PALSAR, followed by Landsat and ERS, and then Landsat and RADARSAT (Figure 5). Correspondingly, most images used for land use assessments were acquired at a medium spatial resolution of 15-100 $\mathrm{m}$ for optical datasets and a high spatial resolution of 4-15 $\mathrm{m}$ for radar datasets (Table 3), and half of the studies (25 of 50) were published in 2010 or after. Note, the categorization of resolution here is arbitrary; it distinguishes typical airborne-data resolutions (e.g., $\leq 4 \mathrm{~m}$ ) and satellite-data resolutions for radar (e.g., $>4$ and $\leq 15 \mathrm{~m}$ ) from other coarser-resolution optical products (e.g., Landsat at $30 \mathrm{~m}$ ). Only two studies, both based in China, used coarse-scale MODIS optical data for assessments, either as the sole optical data source or in combination with Landsat. 


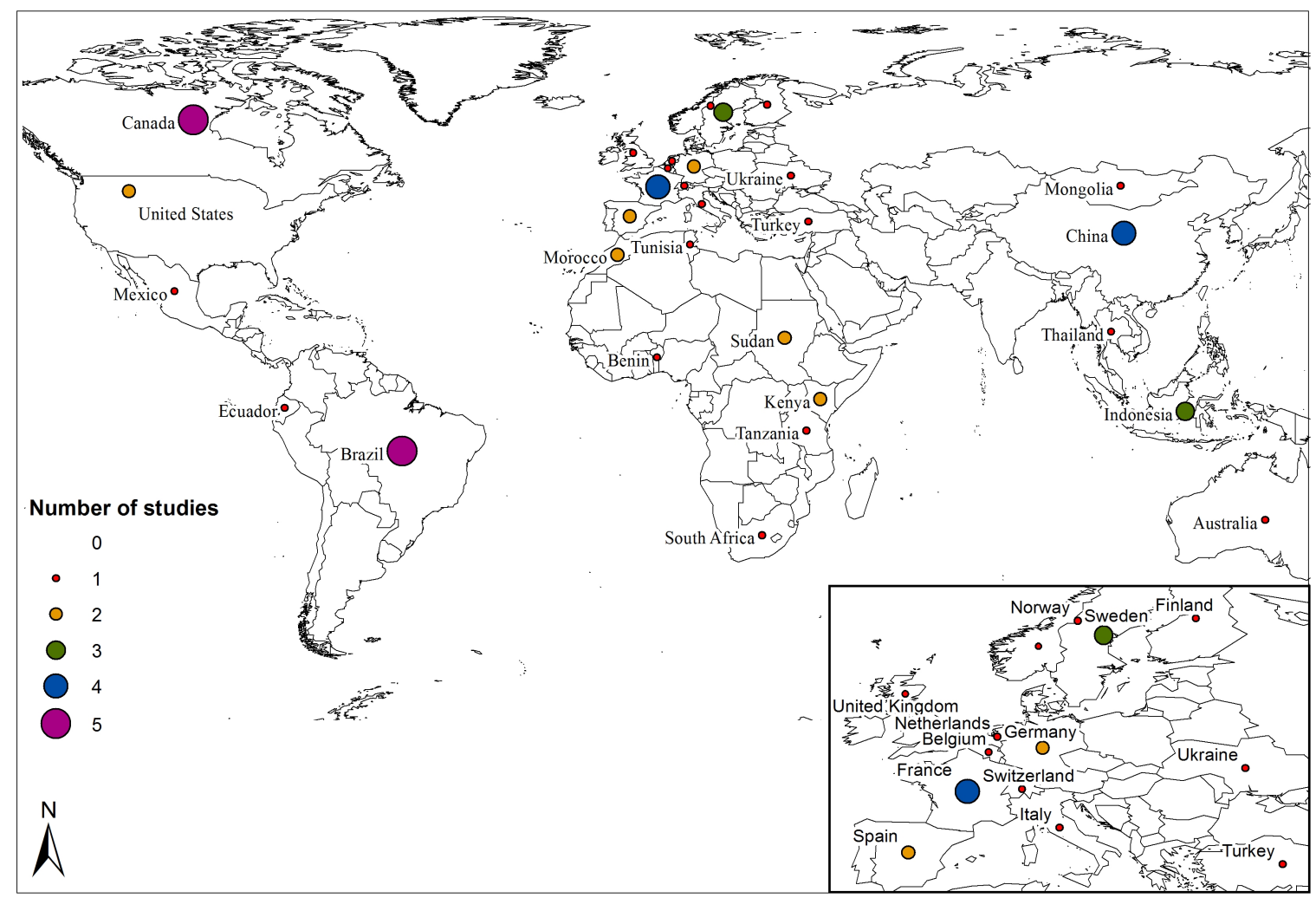

Figure 3. Locations (countries) of study sites in land use-related studies selected for analysis. Studies that covered sites located in more than one country are mapped more than once.



Figure 4. Spatial extent of study sites in land use-related studies selected for analysis. Total area is reported for studies that covered more than one site. Plot level refers to studies that conducted assessments on individual field plots. 


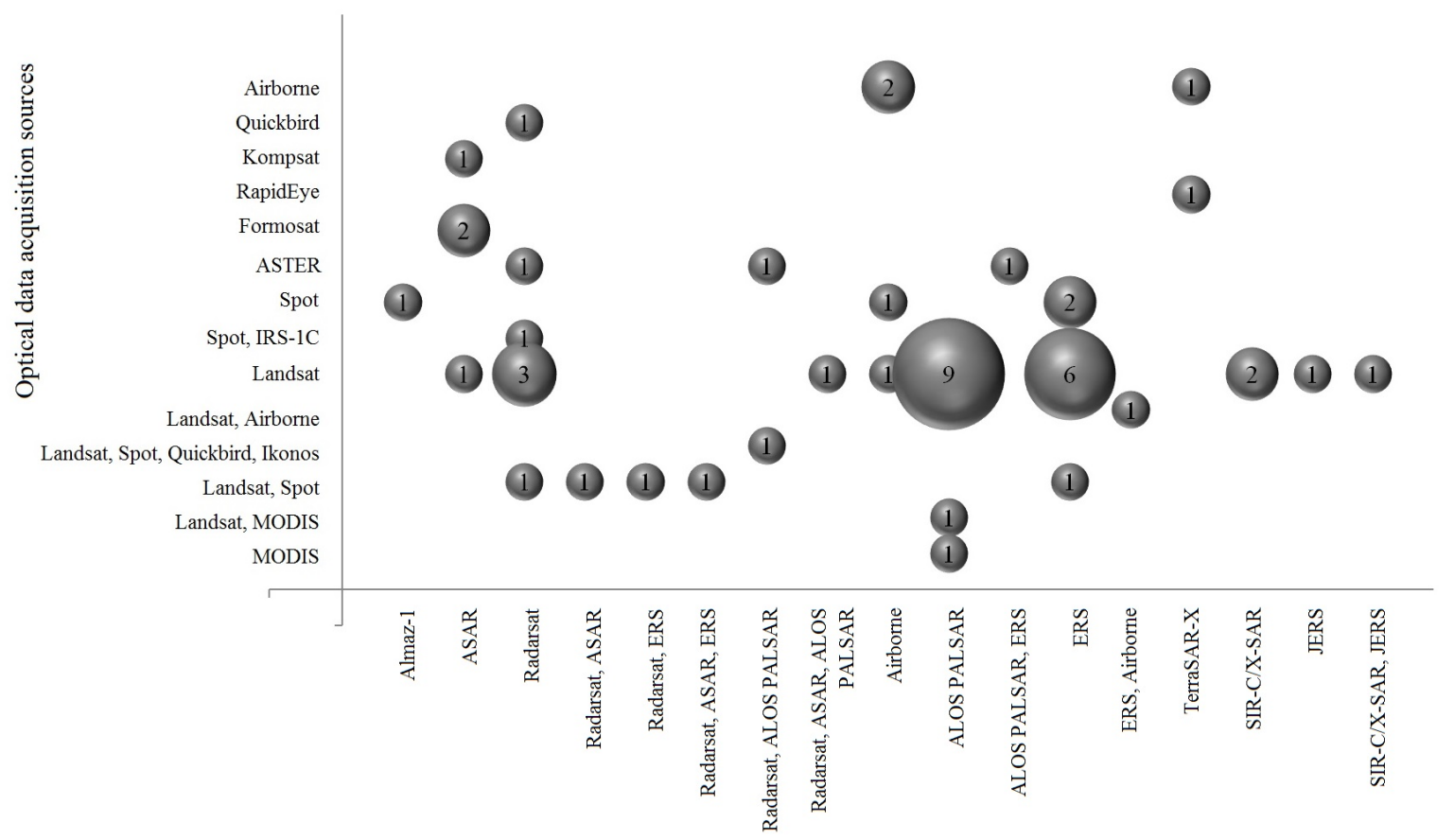

Radar data acquisition sources

Figure 5. Optical- and radar-based sensors used in land use-related studies selected for analysis. Satellites with the same configuration and sensors (e.g., Landsat 4 and Landsat 5 or ERS- 1 and ERS-2) are not distinguished.

Table 3. Spatial scale (image resolution) at which images were acquired in studies including land use assessments. For studies with multiple input data, the coarsest scale is reported. Radar image resolutions refer to ground resolution after multi-looking and projecting acquired scenes. Where studies did not specify scales, the most common scales at which images from the sensors used are acquired were assumed.

\begin{tabular}{|c|c|c|c|c|}
\hline & \multicolumn{2}{|c|}{ Optical Sensor } & \multicolumn{2}{|c|}{ Radar Sensor } \\
\hline & Number of Studies & Study IDs & Number of Studies & Study IDs \\
\hline Very high resolution $(\leq 4 \mathrm{~m})$ & 4 & $(2,19,35,37)$ & 4 & $(13,19,21,37)$ \\
\hline Coarse resolution $(>100 \mathrm{~m})$ & 2 & $(9,47)$ & 0 & \\
\hline
\end{tabular}

\subsection{Specifications of Analyses in Studies Addressing Land Use}

An analysis of the methods used for optical and radar data integration in the 50 studies that specifically addressed aspects of land use (Table 2) was then conducted to answer R3, in sub-questions R3.1-R3.2, as described below.

R3.1. What methods were applied to integrate and analyse data, and did they rely on single or multi-temporal data? 
The range of methods used to integrate optical and radar data was vast. Most studies (28 of 50 studies) analysed the data using traditional classification methods (e.g., Gaussian maximum likelihood classification (MLC), principle component analysis (PCA)). The second most common approach used machine learning techniques (e.g., artificial neural networks, support vector machines), and fewer studies used a knowledge-based, manually-defined decision tree-type method (DT), often to hierarchically combine other classification outputs. Many studies used a variety of combinations of such techniques for optical- or SAR-only image classification (e.g., unsupervised clustering, complex Wishart classification, random forest classifier etc.) and data fusion (e.g., maximum likelihood followed by the iterated conditional modes classifier, k-nearest neighbour algorithm, Dempster-Shafer theory, neural networks etc.). However, very few (ID 1, 12, 29, 30; 4 of 50 studies) test the impact of different data fusion techniques on their outputs. In study ID 1, wavelet-based fusion techniques were found to perform better than multiplicative methods, Brovey transform, PCA, Gram-Schmidt fusion and Ehlers fusion. In study ID 29, it was concluded that nonparametric algorithms, such as classification tree analysis, have the potential to provide better results than MLC. In study ID 30, it was found that MLC and DT classifiers on fused optical-radar datasets generally provided comparable classification accuracies. Finally, 7 studies did not perform classification and instead mapped continuous variables depicting various land properties (Table 4).

Table 4. Summary of methods used in land use-related studies.

\begin{tabular}{lcc}
\hline Classification Method & Number of Studies & Study IDs \\
\hline Traditional & 28 & $\begin{array}{l}(1,2,3,5,11,14,15,20,22,23, \\
25,26,28,29,30,31,32,33,34, \\
35,36,40,41,42,43,44,48,49)\end{array}$ \\
\hline Machine learning & 17 & $\begin{array}{l}(2,4,9,10,12,13,19,20,24, \\
29,30,32,33,37,45,46,50)\end{array}$ \\
\hline Knowledge-based/decision tree & 10 & $(1,2,8,16,17,32,34,42,44,47)$ \\
\hline $\begin{array}{l}\text { Not based on common classification methods } \\
\text { (e.g., regression analysis is used to produce } \\
\text { continuous output variable) }\end{array}$ & 7 & $(6,7,18,21,27,38,39)$ \\
\hline
\end{tabular}

The majority of studies (36 of 50 studies) analysed imagery at the pixel level, i.e., their classification or regression analysis was performed with pixels as the input. A further 10 studies used pixels as the units of analysis, but included information from the wider neighbourhood to assist the algorithm, normally textural information from a surrounding window most often captured from radar (e.g., grey-level co-occurrence matrix measurements (e.g., ID 39, 40)). Finally, 15 studies segmented land into different objects or conducted analysis using statistics within discreet land boundaries (e.g., mean variable value within agricultural field boundaries (ID 38)) and were therefore regarded as analysed at the segment level (Table 5). Most studies simply extracted multi-spectral reflectance values or spectral signatures from optical data and polarized backscatter coefficients from radar data. Studies also often extracted phenological indices, such as leaf area index, fraction of vegetation cover, enhanced vegetation index, NDVI and land surface water index (e.g., ID $2,6,7,9,10,18,38)$, and various band ratios and differences, such as near infrared/green or near infrared/red edge (e.g., ID 13), from optical data. Further, few studies tested extracting information from multi-polarized backscatter ratios and polarimetric decomposition of radar data (e.g., Freeman-Durden and Cloude-Pottier decomposition (ID 10)).

There was a roughly even split between studies that performed analysis on data from a single time period and those that used multi-temporal data ( 23 vs. 27 studies). However, only 5 of the studies with multitemporal data used this information for change detection; for the vast majority of the 27 multi-temporal studies, information was used to assist in creating a mono-temporal output (Table 6). 
Table 5. Scale at which fusion analysis is conducted in land use-related studies.

\begin{tabular}{|c|c|c|}
\hline Scale of Analysis & Number of Studies & Study IDs \\
\hline Pixel-level & 36 & $\begin{array}{c}(1,5,6,7,8,9,10,12,13,16,18, \\
20,21,22,23,24,25,27,28,29, \\
30,32,33,34,35,36,38,40,41, \\
42,43,44,47,48,49,50)\end{array}$ \\
\hline Neighbourhood (e.g., texture windows) & 10 & $\begin{array}{c}(15,16,22,24,25,29,39,40 \\
41,50)\end{array}$ \\
\hline Segment-level & 15 & $\begin{array}{c}(2,3,4,11,13,14,17,19,26 \\
29,31,37,38,45,46)\end{array}$ \\
\hline
\end{tabular}

Table 6. Summary of whether analyses are conducted on static or multi-temporal data in land use-related studies.

\begin{tabular}{|c|c|c|}
\hline Temporal Frequency & Number of Studies & Study IDs \\
\hline Static & 23 & $\begin{array}{c}(1,2,4,7,9,12,15,16,19,20 \\
21,22,23,24,25,29,36,37,39 \\
40,41,44,48)\end{array}$ \\
\hline Multi-temporal & 27 & $\begin{array}{c}(3,5,6,8,10,11,13,14,17,18, \\
26,27,28,30,31,32,33,34,35, \\
38,42,43,45,46,47,49,50)\end{array}$ \\
\hline Studies that also perform change detection & 5 & $(6,14,17,42,43)$ \\
\hline
\end{tabular}

Most studies (37 of 50 studies) integrated optical and radar before classification or modelling, thus letting all information from the input data influence the results, while 16 studies performed a post-classification or post-modelling fusion (Table 7).

Table 7. Summary of the analysis step at which data fusion is performed in land use-related studies.

\begin{tabular}{lcc}
\hline \multicolumn{1}{c}{ Integration Step } & Number of Studies & Study IDs \\
\hline $\begin{array}{l}\text { Pre-classification or -modelling: } \\
\text { fusion of input data }\end{array}$ & 37 & $\begin{array}{r}(1,3,4,7,10,11,13,14,15,16,17,18,21,22,24,25, \\
26,27,28,29,30,31,32,33,35,36,37,38,39,40,41, \\
44,45,46,47,48,50)\end{array}$ \\
\hline $\begin{array}{l}\text { Post-classification or -modelling: } \\
\text { fusion of derived information }\end{array}$ & 16 & $(2,5,6,8,9,12,19,20,23,28,34,37,42,43,44,49)$ \\
\hline $\begin{array}{l}\text { Performed at multiple or different } \\
\text { steps of data processing }\end{array}$ & 3 & $(28,37,44)$ \\
\hline
\end{tabular}

R3.2. Do the studies conclude that data fusion improved results?

Only 32 of the 50 studies directly assessed whether results (i.e., whether classification or continuous output variables) were improved by fusing optical and radar data, compared to using one or the other data source alone. Of these, 28 found that fusing data sources improved results, compared to 4 , which concluded that fused results were identical to or worse than results using just one of the data sources (Table 8).

Although the evaluation of the accuracy of land use and land cover products is important, accuracy assessments cannot be directly compared in this review. Besides the performance of the chosen analyses methods, it was found that studies' results were affected by several differing factors, e.g., land use and land cover types assessed, the quality of the training data and availability of the input imagery, e.g., $[56,99,100]$, as well as the topography and other geographical properties of the study areas. Moreover, accuracy assessments depended heavily on the chosen validation data; 
while some studies used field data, others were based on visual interpretation of high-resolution images, e.g., provided by Google Earth or IKONOS. More generally, assessing accuracy is challenging in the context of LUCC studies, where information on sampling designs, error matrices and accuracy measures, such as user's, producer's and overall accuracy, are not consistently and clearly reported [101,102], and there is still disagreement on reliable indices for measuring accuracy $[103,104]$. Given these complexities and discrepancies, a comparison of accuracy measures reported in the studies was challenging and out of the scope of our review.

Table 8. Summary of the conclusions on whether data integration improves results in land use-related studies.

\begin{tabular}{|c|c|c|}
\hline Conclusion & Number of Studies & Study IDs \\
\hline $\begin{array}{l}\text { Fusion offers an improvement } \\
\text { on a single data type }\end{array}$ & 28 & $\begin{array}{c}(3,5,7,10,11,13,15,17,19,21,22,24,26,28,29 \\
30,33,36,37,40,41,42,43,44,45,48,49,50)\end{array}$ \\
\hline $\begin{array}{l}\text { Fusion results are no different } \\
\text { or worse than using a single } \\
\text { data type }\end{array}$ & 4 & $(4,31,38,39)$ \\
\hline Not compared in sufficient detail & 18 & $\begin{array}{c}(1,2,6,8,9,12,14,16,18,20,23,25,27,32,34 \\
35,46,47)\end{array}$ \\
\hline
\end{tabular}

\section{Discussion}

With increasing availability of optical and radar remote sensing data, research on exploiting the complementarity of the information they provide to study land properties is gaining considerable pace. Besides broadly mapping land cover and land use, recent studies indicate that enhanced information specifically related to land use and the changes therein, which often manifest as only subtle spectral or structural differences on land [30], are detectable with data fusion. Our Web of Science search on such studies revealed that 50 of 112 studies fused radar and optical data for land use assessments, while the rest fused data for land cover assessments. A large majority of these studies ( 28 of 32 studies, which adequately assessed the benefits of fusion) concludes that the accuracy of fused products exceeds those based on single data sources. Although promising, we advise caution that primarily successful and positive results with new methodologies tend to be published, potentially biasing our review in the favour of data fusion. Nevertheless, given the rapid advancement and interest in the field of radar and optical data fusion, and the considerable methodological challenges to combining datasets from sensors that operate on different physical principles, a meta-analysis and systematic review on this subject is timely and crucial for further research.

Contrary to our expectations, the majority of studies that fused radar and optical data restricted analyses to land cover properties as opposed to land use (Table 2). Further, while a number of land use-related studies utilized multi-temporal data (Table 6), it was found that their analyses generally focussed on improving mono-temporal land classifications rather than change detection. This indicates that the move beyond traditionally mapping broad land cover and land use classes (e.g., forest, urban, crop land, etc.), towards extracting and mapping more enhanced land properties that link directly to anthropogenic usage and changes, is yet to be widely implemented in the science of integrating remote sensing products. Several reasons for this can be hypothesized: (1) the field of data fusion is dominated by scholars traditionally focusing on land cover mapping, primarily seeking to test and improve results by fusing data; (2) land use mapping is challenging despite the wealth of remote sensing data available due to the uncertainties inherent in the data sources (e.g., poor spatial resolution, radar speckle, etc.); or (3) broader challenges in analysing and measuring land use (e.g., definitional issues and knowledge gaps in levels and patterns of use) generally limit the ability to understand and characterise land use dynamics [14]. Collecting systematic 
and multi-temporal ground data for calibration and validation of metrics that represent land use (e.g., management strategies, yields or usage cycles) is significantly more challenging than obtaining broad land cover/use properties and a further limitation to land use assessments [30,31].

The lack of studies addressing land use changes may also be attributed to inconsistencies in the spatial and temporal coverage of radar and optical data, and the overall difficulty in acquiring medium-to-long-wavelength SAR (C- or L-band) with sufficient spatial coverage for large-scale studies. The reviewed articles revealed that only spatially small regions (often just the size of a few plots or agricultural fields) across the globe are being studied, with no comparison of methodologies or results across these sites. Moreover, with case studies being conducted primarily in Europe, other highly dynamic areas susceptible to LUCC (e.g., southeast Asia and sub-Saharan Africa [3]) risk remaining understudied if sufficient coverage of remote sensing products is unavailable. Until 2005, studies predominantly used the only available C-band RADARSAT- 1 and ERS- 1 and - 2 satellite data or airborne data. Following the launch of ALOS PALSAR (24 January 2006), L-band satellite data were used for fusion in studies published after 2008. Since then, most commonly in combination with the global and freely-available Landsat series (Figure 5), ALOS PALSAR data have been used for land use assessments in sites across Brazil, Canada, the USA, Spain, Kenya, Sudan, Thailand, Mongolia and China, over an average study area of $>9000 \mathrm{~km}^{2}$. Recently launched SAR sensors (e.g., Sentinel-1 and ALOS-2 PALSAR-2) and those proposed or to be launched soon (e.g., P-band (wavelength $\sim 70 \mathrm{~cm}$ ) BIOMASS, L-band SAOCOM (Satellites for Observation and Communications), Tandem-L and NISAR (NASA-ISRO Synthetic Aperture Radar)) hold enormous potential to expand on such studies, given their higher acquisition frequency and global acquisition strategies.

The methodological differences in the analyses conducted in the reviewed studies were vast, revealing no particular rationale explaining the stage at which fusion between radar and optical datasets was performed (data level or decision level [49]) or in the inputs and types of classification techniques utilized, for the target aims of the reviewed studies. For example, pre-classification fusion followed by using pixels as input in traditional classification methods (e.g., Gaussian MLC, PCA) dominated, irrespective of the themes (e.g., forestry, cropping, wetlands, etc.) addressed and the sensors used in analyses. This indicates that a systematic toolbox of reliable, replicable and spatially-scalable methods of fusing radar and optical data tailored to specific land use assessments (e.g., crop type or logging intensity assessments) and land use changes is lacking in the current literature and is an urgent requirement for future research. In addition, only a handful of reviewed studies assessing land use (four of 50) compared different fusion methodologies in the same study sites, concluding that machine learning or knowledge-based/DT techniques provided comparable or significantly better results than MLC techniques. More studies that evaluate the merits of different processing and classification approaches are urgently needed to guide further research in this field. Another major concern for the widely-used pixel-level analyses of SAR images, particularly for capturing changes in continuous land properties (Figure 1), is speckle. The reduction of speckle may require pre-analysis spatial filtering, often compromising the resolution of outputs. Similarly, multi-temporal filtering can mitigate speckle with minimal loss of radiometric accuracy and spatial resolution of single channels [95,105,106], allowing detection of fine-scaled abrupt changes, but masking more subtle changes (e.g., increased logging frequency or land use intensity). Speckle reduction over areas potentially undergoing very gradual changes over time is a topic that remains largely understudied.

Despite the differences in methodological approaches of the reviewed studies, a large proportion (Table 8) confirmed that the fusion of radar and optical data is beneficial for land use assessments. The themes covered and sensors used in the four studies that concluded no improvement upon data fusion were varied, ranging from mapping crop lands, degraded savannah and forests and using Landsat, ASTER, IRS-1C, SPOT, ALOS PALSAR, RADARSAT and ERS. Three of these studies (ID 4, 31, 38) used data from segmented land boundaries during analysis (done by only 15 of the whole sample of 50 land use-related studies, Table 5), performed fusion prior to 
data analysis (Table 7) and mapped continuous land use variables. In contrast, eight other studies also performed segmentation and fused data prior to classification (ID 3, 11, 13, 17, 26, 29, 37, 45) and found an improvement in results using data fusion. Although this hints that the advantages of fusing radar and optical data are less likely to be expressed when mapping continuous land use properties with fusion at the pixel level or that segment level analysis may not always gain from fusion, the results of the studies must be further interpreted with caution; study ID 4 reports that although SAR attributes did not improve segmentation of savannah physiognomies (e.g., degraded transition zones), land cover was classified more accurately using both optical and radar data by some statistical metrics; study ID 31 reports that multi-date RADARSAT-1 imagery performed equally well as integrated RADARSAT- 1 and IRS-1C to classify crop types, and the acquisition dates of the SPOT imagery used were not ideal to detect crop reflectance differences; study ID 38 reports improvement using fusion in predicting daily net ecosystem exchange in some study sites, but overall improvement in all study sites using radar data alone. This reinforces the idea that both optical and radar data are indeed able to provide useful synergistic information, but there is a need to explore methods and set guidelines for imagery suitable for studying specific themes and aspects of land uses. For this, studies must continue to test multiple methods and data sources within the same sites, as well as attempt to explain if results differ by testing them against truly independent datasets.

Although this review focussed on the fusion of optical and radar remote sensing data alone, other space and airborne technologies, including hyperspectral imaging and light detection and ranging (LiDAR), also bring a rich and powerful database of products that may be used for LUCC, e.g., [107-111]. Combining these with radar and optical datasets can potentially be a major step ahead in the field of land use science. However, such integration methods are either still in infancy or entirely untested, mostly due to the lack, or cost, of remote sensing and ground data for training and validation. In this context, the Landsat series serves as a paramount example of the need to continue the launch of satellites, or airborne surveys, with near-identical sensors, so that multi-decadal time series of complementary data exist; it is the most widely used product for LUCC assessments because of its long period of consistent acquisitions over eight satellites and four decades. Similarly, the very recent addition of Sentinel constellations will provide long-term systematic and consistent data of indispensable value for LUCC analyses [112]. Scientific institutions and policy makers must urge further such approaches towards data acquisition in order to meet the urgent need for continuous and decadal-scale information on global land use.

It is evident that the full potential of optical and radar fusion to examine land use and the subtle changes therein has not yet been explored, despite an increasing availability of data and the urgent need for information on this critical aspect of global environmental change. A few research priorities and recommendations on the way ahead emerge from this review:

- A transition in the science and application of fused remote sensing products, from traditional mapping of broad land cover or use classes to mapping the subtle intricacies of land use management or intensity and the changes therein, is urgently required in support of understanding and accurately quantifying global land use. Future research must be focussed on mapping, for example, land management aspects of cropping cycles, forest harvesting frequencies, paddy and irrigation agriculture, pasture and silvopasture classifications, shrub encroachment on grazing land, etc. Studies must be aimed at similar major global land use transitions, evaluating the most effective spatial scales and methods to fuse optical and radar data using comparable metrics of accuracy.

- In a methodological context, we urge future research to focus on the development of robust optical and radar data fusion techniques, including techniques that test how frequent time series and datasets of varying spatial resolution may be meaningfully merged with minimal information loss. The results of integrating datasets that differ fundamentally in the information they provide must be tested within the same study sites and within the same land use theme 
and be clearly reported as such in future studies. This research will fill a gap in understanding the discord between the chosen methodologies and their accuracies in the current literature.

- Similarly, as studies are implemented across various geographical regions and themes, systematic and standardized procedures for assessing the benefits of fusing data sources need to established. This calls for a standardization of procedures to document accuracy estimates, including uncertainty propagation applicable to the chosen methods of fusion.

- To demonstrate the feasibility of fused datasets to map and monitor global-scale land use change processes, there is an urgent need for studies to be implemented over larger spatial scales (national to continental level) compared to those in the current literature and to be supported with efficient means of data storage and computational processing. Such research will be able to identify the challenges to implementing data integration more clearly, as well as provide a better characterization of large-scale patterns of land use changes and their impacts on climate.

- In support of future airborne and satellite missions aimed at land monitoring, a permanent set of ground-based sites that are frequently monitored for calibration and validation purposes is crucial. Current research is often based on opportunistic availability of data, hence carrying a large variability in ground measurements and resulting in the incomparability of the results between studies. Permanent ground-based measurements will enable more reliable and robust accounts of whether data integration is beneficial, as well as support validating results with datasets that are truly independent from training data.

\section{Conclusions}

This study reviewed the utility of integrating optical and radar remote sensing data, which together combine unique spectral and structural characteristics of land surfaces, for mapping land use and the subtle intricacies of changes in land use management and land use intensity. The key conclusions can be summarized in three points. First, the majority of studies focussed on characterising land cover properties (62 of 112 studies), rather than anthropogenic land uses (50 of 112 studies). Although more than half of the studies that addressed land use utilized multi-temporal data (27 of 50 studies), only a handful (five of 50 studies) attempted to map changes in land use. Only 32 of 50 studies adequately assessed the advantages of data fusion, and the vast majority ( 28 of 32 studies) revealed that data fusion provided results with higher accuracy than using either of the datasets individually. Second, studies that addressed land use were conducted predominantly in Europe (17 of 50 studies) and typically over small regions of $300-3000 \mathrm{~km}^{2}$, with a lack of comparison of fusion techniques across these regions. The themes most commonly studied included cropping, forests/forestry or grasslands/shrublands/pastures; however, there was a lack of frameworks on how to integrate optical and radar datasets for each theme and little information on what land use types the integration would be most effective. Finally, studies that addressed land use most commonly used a methodology that included pre-classification fusion, followed by pixel-level inputs in traditional classification algorithms (e.g., Gaussian MLC, PCA). However, as this field of research is evolving, a plethora of other methods was used often without concrete justifications as to their benefits and without adequate comparisons of different methodologies and their influence on the results. Similarly, accuracies across studies could not be compared due to the vast differences in the datasets and methods used for this purpose.

In conclusion, progress in the field of fusing optical and radar remote sensing data for land use assessments requires the development of: (i) more approaches to map the subtle intricacies of land use management or intensity and the changes therein, rather than only broad land cover or use classifications; (ii) robust techniques to fuse optical and radar data across different ranges of temporal and spatial resolutions, tested over the same study regions and within the same land use themes to ease the comparability of results; (iii) systematic and standardized procedures for assessing the accuracy and benefits of fusing data sources; and (iv) studies conducted over larger spatial scales, supported by efficient computational processing capacity and permanent ground-based sites for 
calibration and validation. These advancements are crucial to quantify global land use and land cover transitions, hence addressing a critical aspect of global environmental change with the best available remote sensing datasets.

Acknowledgments: This study was funded by the Danish Nature Agency and University of Copenhagen. Edward T. A. Mitchard is funded by a grant from the U.K.'s Natural Environment Research Council (NERC, NE/M021998/1). Johannes Reiche is funded through the Horizon 2020 BACI project (Grant Agreement 640176). Matthias Baumann is supported through the FP7-project HERCULES (Grant no. 603447) and the BALTRAK project funded by the Volkswagen Foundation (ProjectRef-No.A112025). Patrick Hostert acknowledges support by the German Federal Ministry of Economy and Infrastructure (BMWi) for the Sense-Carbon Project (project no. 50EE1254). The research presented here contributes to the Global Land Project (http:/ / www.globallandproject.org) and the Landsat Science Team. Tobias Kuemmerle and Matthias Baumann gratefully acknowledge funding by the European Commission (HERCULES, Grant 603447), Volkswagen Foundation (BALTRAK, A112025), the German Research Foundation (KU 2458/5), and the Einstein Foundation Berlin.

Author Contributions: All authors were equally involved in reading, analysing and categorizing the articles reviewed in this study, as well as contributed to writing the review. Neha Joshi coordinated compiling the data, writing and revising the manuscript.

Conflicts of Interest: The authors declare no conflict of interest.

\section{References}

1. Turner, B.L.; Lambin, E.F.; Reenberg, A. The emergence of land change science for global environmental change and sustainability. Proc. Natl. Acad. Sci. USA 2007, 104, 20666-20671.

2. Lambin, E.F.; Geist, H.J. Land-Use and Land-Cover Change Local Processes and Global Impacts; Springer: Berlin, Germany, 2006.

3. Lewis, S.L.; Edwards, D.P.; Galbraith, D. Increasing human dominance of tropical forests. Science 2015, $349,827-832$.

4. DeFries, R.S.; Rudel, T.; Uriarte, M.; Hansen, M. Deforestation driven by urban population growth and agricultural trade in the twenty-first century. Nat. Geosci. 2010, 3, 178-181.

5. Houghton, R.A. How well do we know the flux of $\mathrm{CO}_{2}$ from land-use change? Tellus $B$ 2010, 62, 337-351.

6. World Resources Institute. Millennium Ecosystem Assessment, 2005. In Ecosystems and Human Well-being: Synthesis; World Resources Institute: Washington, DC, USA, 2005.

7. Sombroek, W. Spatial and Temporal Patterns of Amazon Rainfall. Ambio 2001, 30, 388-396.

8. Luyssaert, S.; Jammet, M.; Stoy, P.C.; Estel, S.; Pongratz, J.; Ceschia, E.; Churkina, G.; Don, A.; Erb, K.; Ferlicoq, M.; et al. Land management and land-cover change have impacts of similar magnitude on surface temperature. Nat. Clim. Chang. 2014, 4, 389-393.

9. United Nations Framework Convention on Climate Change. Report of the Conference of the Parties on Its Thirteenth Session. In Proceedings of the United Nations Climate Change Conference, Bali, Indonesia, 3-15 December 2007.

10. United Nations Framework Convention on Climate Change. Fact Sheet: Reducing Emissions From Deforestation in Developing Countries: Approaches To Stimulate Action; UNFCCC: Durban, South Africa, 2011.

11. Joshi, N.; Mitchard, E.T.; Woo, N.; Torres, J.; Moll-Rocek, J.; Ehammer, A.; Collins, M.; Jepsen, M.R.; Fensholt, R. Mapping dynamics of deforestation and forest degradation in tropical forests using radar satellite data. Environ. Res. Lett. 2015, 10, 034014.

12. DeFries, R.S.; Townshend, J.R.G.; Hansen, M.C. Continuous fields of vegetation characteristics at the global scale at 1-km resolution. J. Geophys. Res. Atmos. 1999, 104, 16911-16923.

13. Hansen, M.C.; DeFries, R.S. Detecting Long-term Global Forest Change Using Continuous Fields of Tree-Cover Maps from 8-km Advanced Very High Resolution Radiometer (AVHRR) Data for the Years 1982-99. Ecosystems 2004, 7, 695-716.

14. Erb, K.H.; Haberl, H.; Jepsen, M.R.; Kuemmerle, T.; Lindner, M.; MÃijller, D.; Verburg, P.H.; Reenberg, A. A conceptual framework for analysing and measuring land-use intensity. Curr. Opin. Environ. Sustain. 2013, $5,464-470$.

15. O'Connor, T.G.; Puttick, J.R.; Hoffman, M.T. Bush encroachment in southern Africa: Changes and causes. Afr. J. Range Forage Sci. 2014, 31, 67-88. 
16. Bond, W.J.; Midgley, G.F. Carbon dioxide and the uneasy interactions of trees and savannahh grasses. Philos. Trans. R. Soc. Lond. B Biol. Sci. 2012, 367, 601-612.

17. Myers-Smith, I.H.; Forbes, B.C.; Wilmking, M.; Hallinger, M.; Lantz, T.; Blok, D.; Tape, K.D.; Macias-Fauria, M.; Sass-Klaassen, U.; Lévesque, E.; et al. Shrub expansion in tundra ecosystems: Dynamics, impacts and research priorities. Environ. Res. Lett. 2011, 6, 045509.

18. Mitchard, E.T.A.; Flintrop, C.M. Woody encroachment and forest degradation in sub-Saharan Africa's woodlands and savannahs 1982-2006. Philos. Trans. R. Soc. Lond. B Biol. Sci. 2013, 368.

19. Brandt, M.; Mbow, C.; Diouf, A.A.; Verger, A.; Samimi, C.; Fensholt, R. Ground- and satellite-based evidence of the biophysical mechanisms behind the greening Sahel. Glob. Chang. Biol. 2015, 21, 1610-1620.

20. Herrmann, S.; Tappan, G. Vegetation impoverishment despite greening: A case study from central Senegal. J. Arid Environ. 2013, 90, 55-66.

21. Townshend, J.; Justice, C.; Li, W.; Gurney, C.; McManus, J. Global land cover classification by remote sensing: Present capabilities and future possibilities. Remote Sens. Environ. 1991, 35, 243-255.

22. Loveland, T.R.; Reed, B.C.; Brown, J.F.; Ohlen, D.O.; Zhu, Z.; Yang, L.; Merchant, J.W. Development of a global land cover characteristics database and IGBP DISCover from $1 \mathrm{~km}$ AVHRR data. Int. J. Remote Sens. 2000, 21, 1303-1330.

23. Friedl, M.; McIver, D.; Hodges, J.; Zhang, X.; Muchoney, D.; Strahler, A.; Woodcock, C.; Gopal, S.; Schneider, A.; Cooper, A.; et al. Global land cover mapping from MODIS: Algorithms and early results. Remote Sens. Environ. 2002, 83, 287-302.

24. Mayaux, P.; Bartholomé, E.; Fritz, S.; Belward, A. A new land-cover map of Africa for the year 2000. J. Biogeogr. 2004, 31, 861-877.

25. Bicheron, P.; Defourny, P.; Brockmann, C.; Schouten, L.; Vancutsem, C.; Huc, M.; Bontemps, S.; Leroy, M.; Achard, F.; Herold, M.; et al. GLOBCOVER: Products Description and Validation Report; MEDIAS-France: Toulouse, France, 2008.

26. Hansen, M.C.; Potapov, P.V.; Moore, R.; Hancher, M.; Turubanova, S.A.; Tyukavina, A.; Thau, D.; Stehman, S.V.; Goetz, S.J.; Loveland, T.R.; et al. High-Resolution Global Maps of 21st-Century Forest Cover Change. Science 2013, 342, 850-853.

27. Ryan, C.M.; Berry, N.J.; Joshi, N. Quantifying the causes of deforestation and degradation and creating transparent REDD+ baselines: A method and case study from central Mozambique. Appl. Geogr. 2014, 53, 45-54.

28. Brolly, M.; Woodhouse, I.H. A "Matchstick" Model of microwave backscatter from a forest. Ecol. Model. 2012, 237-238, 74-87.

29. Giri, C.P. Remote Sensing of Land Use and Land Cover: Principles and Applications; CRC Press, Taylor and Francis Group: Boca Raton, FL, USA, 2012.

30. Kuemmerle, T.; Erb, K.; Meyfroidt, P.; Müller, D.; Verburg, P.H.; Estel, S.; Haberl, H.; Hostert, P.; Jepsen, M.R.; Kastner, T.; et al. Challenges and opportunities in mapping land use intensity globally. Curr. Opin. Environ. Sustain. 2013, 5, 484-493.

31. Zaks, D.P.M.; Kucharik, C.J. Data and monitoring needs for a more ecological agriculture. Environ. Res. Lett. 2011, 6, 014017.

32. Verburg, P.H.; Neumann, K.; Nol, L. Challenges in using land use and land cover data for global change studies. Glob. Chang. Biol. 2011, 17, 974-989.

33. Malenovský, Z.; Rott, H.; Cihlar, J.; Schaepman, M.E.; García-Santos, G.; Fernandes, R.; Berger, M. Sentinels for science: Potential of Sentinel-1, -2, and -3 missions for scientific observations of ocean, cryosphere, and land. Remote Sens. Environ. 2012, 120, 91-101.

34. Tupin, F. Fusion of Optical and SAR images. In Radar Remote Sensing of Urban Areas; Soergel, U., Ed.; Springer: Amsterdam, The Netherlands, 2010.

35. Engdahl, M.; Hyyppa, J. Land-cover classification using multitemporal ERS-1/2 InSAR data. IEEE Trans. Geosci. Remote Sens. 2003, 41, 1620-1628.

36. Hong, S.H.; Wdowinski, S. Multitemporal multitrack monitoring of wetland water levels in the Florida Everglades using ALOS PALSAR data with interferometric processing. IEEE Geosci. Remote Sens. Lett. 2014, 11, 1355-1359. 
37. Meyfroidt, P.; Carlson, K.M.; Fagan, M.E.; Gutiérrez-Vélez, V.H.; Macedo, M.N.; Curran, L.M.; DeFries, R.S.; Dyer, G.A.; Gibbs, H.K.; Lambin, E.F.; et al. Multiple pathways of commodity crop expansion in tropical forest landscapes. Environ. Res. Lett. 2014, 9, 074012.

38. Graesser, J.; Aide, T.M.; Grau, H.R.; Ramankutty, N. Cropland/pastureland dynamics and the slowdown of deforestation in Latin America. Environ. Res. Lett. 2015, 10, 034017.

39. Lark, T.J.; Salmon, J.M.; Gibbs, H.K. Cropland expansion outpaces agricultural and biofuel policies in the United States. Environ. Res. Lett. 2015, 10, 044003.

40. Lambin, E.F.; Meyfroidt, P.; Rueda, X.; Blackman, A.; Börner, J.; Cerutti, P.O.; Dietsch, T.; Jungmann, L.; Lamarque, P.; Lister, J.; et al. Effectiveness and synergies of policy instruments for land use governance in tropical regions. Glob. Environ. Chang. 2014, 28, 129-140.

41. Gibbs, H.K.; Rausch, L.; Munger, J.; Schelly, I.; Morton, D.C.; Noojipady, P.; Soares-Filho, B.; Barreto, P.; Micol, L.; Walker, N.F. Brazil's Soy Moratorium. Science 2015, 347, 377-378.

42. Amarsaikhan, D.; Ganzorig, M.; Ache, P.; Blotevogel, H. The integrated use of optical and InSAR data for urban land-cover mapping. Int. J. Remote Sens. 2007, 28, 1161-1171.

43. Waske, B.; van der Linden, S. Classifying multilevel imagery from SAR and optical sensors by decision fusion. IEEE Trans. Geosci. Remote Sens. 2008, 46, 1457-1466.

44. Erasmi, S.; Twele, A. Regional land cover mapping in the humid tropics using combined optical and SAR satellite dataa case study from Central Sulawesi, Indonesia. Int. J. Remote Sens. 2009, 30, 2465-2478.

45. Pereira, L.D.O.; Freitas, C.D.C.; St Anna, S.J.S.; Lu, D.; Moran, E.F. Optical and radar data integration for land use and land cover mapping in the Brazilian Amazon. GISci. Remote Sens. 2013, 50, 301-321.

46. Stefanski, J.; Kuemmerle, T.; Chaskovskyy, O.; Griffiths, P.; Havryluk, V.; Knorn, J.; Korol, N.; Sieber, A.; Waske, B. Mapping land management regimes in western Ukraine using optical and SAR data. Remote Sens. 2014, 6, 5279-5305.

47. Dusseux, P.; Corpetti, T.; Hubert-Moy, L.; Corgne, S. Combined use of multi-temporal optical and radar satellite images for grassland monitoring. Remote Sens. 2014, 6, 6163-6182.

48. Richards, J. Analysis of remotely sensed data: The formative decades and the future. IEEE Trans. Geosci. Remote Sens. 2005, 43, 422-432.

49. Pohl, C.; Genderen, J.L.V. Review article multisensor image fusion in remote sensing: Concepts, methods and applications. Int. J. Remote Sens. 1998, 19, 823-854.

50. Lu, D.; Weng, Q. A survey of image classification methods and techniques for improving classification performance. Int. J. Remote Sens. 2007, 28, 823-870.

51. Wald, L. Some terms of reference in data fusion. IEEE Trans. Geosci. Remote Sens. 1999, 37, 1190-1193.

52. Brisco, B.; Brown, R.J. Multidate SAR/TM synergism for crop classification in western Canada. Photogramm. Eng. Remote Sens. 1995, 61, 1009-1014.

53. Chust, G.; Ducrot, D.; Pretus, J.L. Land cover discrimination potential of radar multitemporal series and optical multispectral images in a Mediterranean cultural landscape. Int. J. Remote Sens. 2004, 25, 3513-3528.

54. Huang, H.; Legarsky, J.; Othman, M. Land-cover classification using Radarsat and Landsat iImagery for St. Louis, Missouri. Photogramm. Eng. Remote Sens. 2007, 73, 37-43.

55. Benediktsson, J.; Kanellopoulos, I. Classification of multisource and hyperspectral data based on decision fusion. IEEE Trans. Geosci. Remote Sens. 1999, 37, 1367-1377.

56. Waske, B.; Benediktsson, J. Fusion of support vector machines for classification of multisensor data. IEEE Trans. Geosci. Remote Sens. 2007, 45, 3858-3866.

57. Zhang, H.; Lin, H.; Li, Y. Impacts of feature normalization on optical and SAR data fusion for land use/land cover classification. IEEE Geosci. Remote Sens. 2015, 12, 1061-1065.

58. Griffiths, P.; Kuemmerle, T.; Baumann, M.; Radeloff, V.C.; Abrudan, I.V.; Lieskovsky, J.; Munteanu, C.; Ostapowicz, K.; Hostert, P. Forest disturbances, forest recovery, and changes in forest types across the Carpathian ecoregion from 1985 to 2010 based on Landsat image composites. Remote Sens. Environ. 2014, $151,72-88$.

59. Homer, C.; Dewitz, J.; Fry, J.; Coan, M.; Hossain, N.; Larson, C.; Herold, N.; McKerrow, A.; VanDriel, J.N.; Wickham, J. Completion of the 2001 national land cover database for the conterminous United States. Photogramm. Eng. Remote Sens. 2007, 73, 337-341.

60. Morton, D.; Rowland, C.; Wood, C.; Meek, L.; Marston, C.; Smith, G.; Wadsworth, R.; Simpson, I.C. Final Report for LCM2007-The New UK Land Cover Map; Countryside Survey: Edinburgh, UK, 2011. 
61. Arino, O.; Bicheron, P.; Achard, F.; Latham, J.; Witt, R.; Weber, J.L. GLOBCOVER—The Most Detailed Portrait of Earth; ESA Directorate of Earth Observation Programmes: Frascati, Italy, 2008.

62. Bartholomé, E.; Belward, A.S. GLC2000: A new approach to global land cover mapping from Earth observation data. Int. J. Remote Sens. 2005, 26, 1959-1977.

63. Hansen, M.C.; Defries, R.S.; Townshend, J.R.G.; Sohlberg, R. Global land cover classification at 1 km spatial resolution using a classification tree approach. Int. J. Remote Sens. 2000, 21, 1331-1364.

64. Friedl, M.A.; Sulla-Menashe, D.; Tan, B.; Schneider, A.; Ramankutty, N.; Sibley, A.; Huang, X. MODIS Collection 5 global land cover: Algorithm refinements and characterization of new datasets. Remote Sens. Environ. 2010, 114, 168-182.

65. Estel, S.; Kuemmerle, T.; Alcántara, C.; Levers, C.; Prishchepov, A.; Hostert, P. Mapping farmland abandonment and recultivation across Europe using MODIS NDVI time series. Remote Sens. Environ. 2015, 163, 312-325.

66. Griffiths, P.; Kuemmerle, T.; Kennedy, R.E.; Abrudan, I.V.; Knorn, J.; Hostert, P. Using annual time-series of Landsat images to assess the effects of forest restitution in post-socialist Romania. Remote Sens. Environ. 2012, 118, 199-214.

67. Souchère, V.; King, C.; Dubreuil, N.; Lecomte-Morel, V.; Bissonnais, Y.L.; Chalat, M. Grassland and crop trends: Role of the European Union Common Agricultural Policy and consequences for runoff and soil erosion. Environ. Sci. Policy 2003, 6, 7-16.

68. Kovalskyy, V.; Roy, D. The global availability of Landsat 5 TM and Landsat 7 ETM+ land surface observations and implications for global $30 \mathrm{~m}$ Landsat data product generation. Remote Sens. Environ. 2013, 130, 280-293.

69. Roy, D.; Wulder, M.; Loveland, T.R.; Woodcock, C.E.; Allen, R.; Anderson, M.; Helder, D.; Irons, J.; Johnson, D.; Kennedy, R.; et al. Landsat-8: Science and product vision for terrestrial global change research. Remote Sens. Environ. 2014, 145, 154-172.

70. Hostert, P.; Griffiths, P.; van der Linden, S.; Pflugmacher, D. Time series analyses in a New Era of optical satellite data. Remote Sens. Time Ser. 2015, 22, 25-41.

71. Carrão, H.; Gonçalves, P.; Caetano, M. Contribution of multispectral and multitemporal information from MODIS images to land cover classification. Remote Sens. Environ. 2008, 112, 986-997.

72. Clark, M.L.; Aide, T.M.; Grau, H.R.; Riner, G. A scalable approach to mapping annual land cover at $250 \mathrm{~m}$ using MODIS time series data: A case study in the Dry Chaco ecoregion of South America. Remote Sens. Environ. 2010, 114, 2816-2832.

73. Shimada, M.; Itoh, T.; Motooka, T.; Watanabe, M.; Shiraishi, T.; Thapa, R.; Lucas, R. New global forest/non-forest maps from ALOS PALSAR data (2007-2010). Remote Sens. Environ. 2014, 155, 13-31.

74. Cable, J.W.; Kovacs, J.M.; Shang, J.; Jiao, X. Multi-Temporal polarimetric RADARSAT-2 for land cover monitoring in Northeastern Ontario, Canada. Remote Sens. 2014, 6, 2372-2392.

75. Simard, M.; Saatchi, S.; de Grandi, G. The use of decision tree and multiscale texture for classification of JERS-1 SAR data over tropical forest. IEEE Trans. Geosci. Remote Sens. 2000, 38, 2310-2321.

76. Mitchard, E.T.; Meir, P.; Ryan, C.M.; Woollen, E.S.; Williams, M.; Goodman, L.E.; Mucavele, J.A.; Watts, P.; Woodhouse, I.H.; Saatchi, S.S. A novel application of satellite radar data: Measuring carbon sequestration and detecting degradation in a community forestry project in Mozambique. Plant Ecol. Divers. 2013, 6, 159-170.

77. Ryan, C.M.; Hill, T.; Woollen, E.; Ghee, C.; Mitchard, E.; Cassells, G.; Grace, J.; Woodhouse, I.H.; Williams, M. Quantifying small-scale deforestation and forest degradation in African woodlands using radar imagery. Glob. Chang. Biol. 2012, 18, 243-257.

78. Whittle, M.; Quegan, S.; Uryu, Y.; Stueewe, M.; Yulianto, K. Detection of tropical deforestation using ALOS-PALSAR: A Sumatran case study. Remote Sens. Environ. 2012, 124, 83-98.

79. Henderson, F.; Xia, Z.G. SAR applications in human settlement detection, population estimation and urban land use pattern analysis: A status report. IEEE Trans. Geosci. Remote Sens. 1997, 35, 79-85.

80. Wu, W.; Guo, H.; Li, X.; Ferro-Famil, L.; Zhang, L. Urban land use information extraction using the ultrahigh-resolution Chinese airborne SAR imagery. IEEE Trans. Geosci. Remote Sens. 2015, 53, 5583-5599.

81. Bargiel, D.; Herrmann, S. Multi-Temporal land-cover classification of agricultural areas in two European regions with high resolution Spotlight TerraSAR-X Data. Remote Sens. 2011, 3, 859-877.

82. Ribbes, F. Rice field mapping and monitoring with RADARSAT data. Int. J. Remote Sens. 1999, $20,745-765$. 
83. Inoue, Y.; Kurosu, T.; Maeno, H.; Uratsuka, S.; Kozu, T.; Dabrowska-Zielinska, K.; Qi, J. Season-long daily measurements of multifrequency $(\mathrm{Ka}, \mathrm{Ku}, \mathrm{X}, \mathrm{C}$, and $\mathrm{L})$ and full-polarization backscatter signatures over paddy rice field and their relationship with biological variables. Remote Sens. Environ. 2002, 81, 194-204.

84. Bouvet, A.; Toan, T.L. Use of ENVISAT/ASAR wide-swath data for timely rice fields mapping in the Mekong River Delta. Remote Sens. Environ. 2011, 115, 1090-1101.

85. Blaes, X.; Vanhalle, L.; Defourny, P. Efficiency of crop identification based on optical and SAR image time series. Remote Sens. Environ. 2005, 96, 352-365.

86. McNairn, H.; Shang, J.; Jiao, X.; Champagne, C. The contribution of ALOS PALSAR multipolarization and polarimetric data to crop classification. IEEE Trans. Geosci. Remote Sens. 2009, 47, 3981-3992.

87. Price, K.P.; Guo, X.; Stiles, J.M. Comparison of Landsat TM and ERS-2 SAR data for discriminating among grassland types and treatments in eastern Kansas. Comput. Electron. Agric. 2002, 37, 157-171.

88. Asner, G.P. Cloud cover in Landsat observations of the Brazilian Amazon. Int. J. Remote Sens. 2001, 22, 3855-3862.

89. Chambers, J.Q.; Asner, G.P.; Morton, D.C.; Anderson, L.O.; Saatchi, S.S.; Espírito-Santo, F.D.; Palace, M.; Souza, C., Jr. Regional ecosystem structure and function: Ecological insights from remote sensing of tropical forests. Trends Ecol. Evol. 2007, 22, 414-423.

90. Sannier, C.; McRoberts, R.E.; Fichet, L.V.; Makaga, E.M.K. Using the regression estimator with Landsat data to estimate proportion forest cover and net proportion deforestation in Gabon. Remote Sens. Environ. 2014, 151, 138-148.

91. Pflugmacher, D.; Cohen, W.B.; Kennedy, R.E. Using Landsat-derived disturbance history (1972-2010) to predict current forest structure. Remote Sens. Environ. 2012, 122, 146-165.

92. Rogana, J.; Chenb, D.M. Remote sensing technology for mapping and monitoring land-cover and land-use change. Prog. Plan. 2004, 61, 301-325.

93. Maghsoudi, Y.; Collins, M.J.; Leckie, D. Speckle reduction for the forest mapping analysis of multi-temporal Radarsat-1 images. Int. J. Remote Sens. 2012, 33, 1349-1359.

94. Lopes, A.; Touzi, R.; Nezry, E. Adaptive speckle filters and scene heterogeneity. IEEE Trans. Geosci. Remote Sens. 1990, 28, 992-1000.

95. Quegan, S.; Yu, J.J. Filtering of multichannel SAR images. IEEE Trans. Geosci. Remote Sens. 2001, 39, 2373-2379.

96. Woodhouse, I. Introduction to Microwave Remote Sensing; CRC Press Taylor \& Francis Group: Boca Raton, FL, USA, 2006.

97. Rosenqvist, A.; Shimada, M.; Ito, N.; Watanabe, M. ALOS PALSAR: A pathfinder mission for global-scale monitoring of the environment. IEEE Trans. Geosci. Remote Sens. 2007, 45, 3307-3316.

98. Reiche, J.; de Bruin, S.; Hoekman, D.; Verbesselt, J.; Herold, M. A Bayesian approach to combine Landsat and ALOS PALSAR time series for near real-time deforestation detection. Remote Sens. 2015, 7, 4973-4996.

99. Pal, M.; Mather, P.M. Some issues in the classification of DAIS hyperspectral data. Int. J. Remote Sens. 2006, 27, 2895-2916.

100. Foody, G.M.; Mathur, A. The use of small training sets containing mixed pixels for accurate hard image classification: Training on mixed spectral responses for classification by a SVM. Remote Sens. Environ. 2006, 103, 179-189.

101. Olofsson, P.; Foody, G.M.; Stehman, S.V.; Woodcock, C.E. Making better use of accuracy data in land change studies: Estimating accuracy and area and quantifying uncertainty using stratified estimation. Remote Sens. Environ. 2013, 129, 122-131.

102. Wagner, J.E.; Stehman, S.V. Optimizing sample size allocation to strata for estimating area and map accuracy. Remote Sens. Environ. 2015, 168, 126-133.

103. Foody, G.M. Status of land cover classification accuracy assessment. Remote Sens. Environ. 2002, 80, 185-201.

104. Pontius, R.G., Jr.; Millones, M. Death to Kappa: Birth of quantity disagreement and allocation disagreement for accuracy assessment. Int. J. Remote Sens. 2011, 32, 4407-4429.

105. Quegan, S.; Yu, J.J.; LeToan, T. Iterated multi-channel filtering of SAR images. In Proceedings of the IEEE 2000 International Geoscience and Remote Sensing Symposium (IGARSS), Honolulu, HI, USA, 24-28 July 2000; Volume 2, pp. 657-659. 
106. Trouve, E.; Chambenoit, Y.; Classeau, N.; Bolon, P. Statistical and operational performance assessment of multitemporal SAR image filtering. IEEE Trans. Geosci. Remote Sens. 2003, 41, 2519-2530.

107. Long, D.S.; McCallum, J.D. On-combine, multi-sensor data collection for post-harvest assessment of environmental stress in wheat. Precis. Agric. 2015, 16, 492-504.

108. Man, Q.; Dong, P.; Guo, H. Pixel- and feature-level fusion of hyperspectral and lidar data for urban land-use classification. Int. J. Remote Sens. 2015, 36, 1618-1644.

109. Jones, T.G.; Coops, N.C.; Sharma, T. Assessing the utility of airborne hyperspectral and LiDAR data for species distribution mapping in the coastal Pacific Northwest, Canada. Remote Sens. Environ. 2010, 114, 2841-2852.

110. Hladik, C.; Schalles, J.; Alber, M. Salt marsh elevation and habitat mapping using hyperspectral and LIDAR data. Remote Sens. Environ. 2013, 139, 318-330.

111. Yokoya, N.; Nakazawa, S.; Matsuki, T.; Iwasaki, A. Fusion of hyperspectral and LiDAR data for landscape visual quality assessment. IEEE J. Sel. Top. Appl. Earth Obs. Remote Sens. 2014, 7, 2419-2425.

112. Berger, M.; Moreno, J.; Johannessen, J.A.; Levelt, P.F.; Hanssen, R.F. ESA's sentinel missions in support of Earth system science. Remote Sens. Environ. 2012, 120, 84-90.

(C) 2016 by the authors; licensee MDPI, Basel, Switzerland. This article is an open access article distributed under the terms and conditions of the Creative Commons by Attribution (CC-BY) license (http://creativecommons.org/licenses/by/4.0/). 